\title{
Research on Foreign Trade English Correspondence Communication Effectiveness of Foreign Trade Enterprises in Guangxi Beibu Gulf Economic Zone
}

\author{
Suping Jiang \\ Guangxi Talent International College, Qinzhou Guangxi 535000, China. \\ janliful@163.com
}

Keywords: Guangxi; economic zone; trade enterprises; correspondence communication.

\begin{abstract}
With the construction and rapid development of Guangxi Beibu Gulf Economic Zone, a large number of transnational corporations are making trade contacts in Guangxi, which intensifies the diversification trend of enterprise culture background, and the cross-cultural communication and exchange have become increasingly important while the cultural communication and collision of multiple cultures will certainly cause more and more cross-cultural conflicts thus to form cross-cultural communication barriers. Especially for the foreign trade English correspondence communication of foreign trade enterprises, how to overcome the conflict with different cultures to the largest extent under the cross-cultural situation, eliminate the communication barriers, realize effective cross-cultural communication and enhance the correspondence communication effectiveness has become a core problem for enterprises' transnational operation, which is of positive practical significance to the Chinese enterprises going out to integrate into global economy. This paper conducts analysis based on the current situation of foreign trade English correspondence communication under the cross-cultural underground, combined with the foreign trade characteristic of Guangxi Beibu Gulf Economic Zone, puts forward some effective suggestions on enhancing foreign trade correspondence effectiveness.
\end{abstract}

\section{Introduction}

Cross-cultural communication refers to the communication between people having different cultural backgrounds. When the communication sender has one kind of cultural background while the receiver has another kind of cultural background, the mutual influence between them is the process of cross-cultural communication. Inside the transnational corporations, the cultures of host country and the occurrence country cross-link and combine with each other, the larger the cultural difference between the managers and staff from different countries as well as from the host country and occurrence country is, the larger the communication barrier is. With the construction and rapid development of Guangxi Beibu Gulf Economic Zone, for the foreign trade English correspondence communication of foreign trade enterprises, how to realize cross-cultural communication effectively and enhance the correspondence communication effectiveness has become a core problem for enterprises' transnational operation.

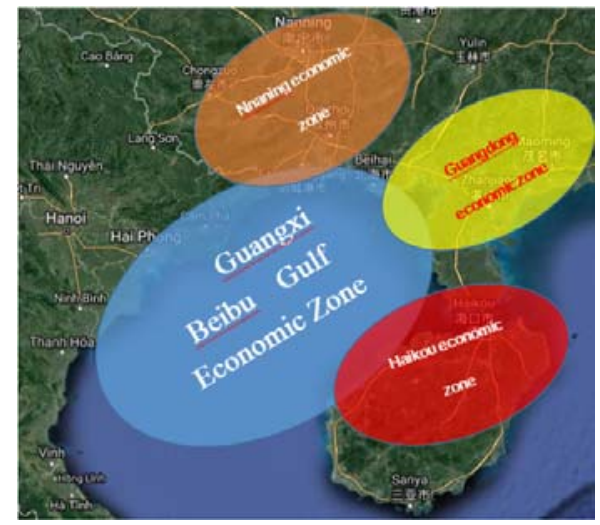

Fig 1. Guangxi beibu gulf economic zone 


\section{Current Problems Existed in Foreign Trade Correspondence Communication of Chinese Enterprises}

\subsection{The Foreign Trade Correspondence Communication Capability Is Generally Weal.}

Most overseas enterprises of our country lack of foreign trade correspondence communication awareness, pay less attention to enhancing cross-cultural communication capability, get used to adopting local language culture for publicity and have weak capability in foreign trade correspondence communication. The main reflections include no popularity of large number of high-quality Chinese brand products in international market and low position in the heart of the public. Most enterprises make no publicity on brand advertisement and enterprise products through the popular media such as international newspapers and periodicals, TV and film and internet. For the China-invested enterprises, only some insiders know their name, brands, product technology and product quality, while the public generally know nothing about their basic situations. Most Chinese enterprises provide no English or host country language-based websites on their websites, and some websites are not updated for long time with dull contents and without characteristics.

\subsection{Neglect the Cultural Difference and Exist With Language Culture Barriers of Different Degrees.}

In recent years, many Chinese enterprises have adopted internationalized marketing strategy. It should be mentioned that Chinese enterprises are good at production and operation but pay less attention to cultural difference. Owing to the large difference in culture and knowing nothing about the local system, laws and regulations, operation conventions and social awareness, Chinese enterprises often face poor operation. In addition, the largest barrier for people having different cultural backgrounds in communication lies in the different languages. Chinese enterprises often face the language communication barrier in overseas operation. Translators are needed for the communication between the people knowing nothing about the language of host country or the foreign mangers and the staff, which makes the communication process complicated and difficult, and even the intentional meaning cannot be transmitted to the opposite side to cause information losing, distortion and misunderstanding.

\subsection{Lack of Training on Foreign Trade Correspondence Communication and Management.}

Owing to the lack of talents owing cross-cultural knowledge and experience in managing foreign employees, Chinese enterprises face barriers in the globalization process. In the past few decades, China has not accumulated a large batch of excellent transnational operation management talents. Many enterprises are not willing to invest in the training on foreign trade correspondence communication, and they lack of understanding of the important significance of overseas enterprises in carrying out cross-cultural communication and management training as well as the key role of enhancing foreign trade correspondence communication capability in successful operation of enterprises. Among the senior managers of Chinese enterprises, half of them accept no cross-cultural training, on the contrary, the transnational corporations of developed countries often take such kind of overseas work experience as the necessary situation for position promotion. Some managers of China-invested enterprises lack of globalization experience and tend to make no positive communication in face of problems in overseas, which makes them lose the speaking right, they tend to lose their hand in face of communication misunderstanding.

\subsection{Chinese Culture Has Weak Position in Overseas.}

Chinese culture not only has no advantage in global culture competition but also is increasingly penetrated by western culture. Besides, it has large difficulty in exporting in the expanded competition among different cultural forces, which has less penetration force and influence than the western culture. As a country of weak culture, when Chinese enterprises engage in transnational operation in the developed countries of Europe and America with strong culture, the local employees have strong superiority complex and have low degree of recognition on Chinese enterprise culture, therefore, you can imagine the difficulties and barriers in communication. If Chinese enterprises impose their own cultures to the local employees, the conflict certainly will appear. 


\section{Analysis on Communication Barrier Under the Cross-Cultural Perspective}

\subsection{Difference in Value and Way of Thinking.}

In the foreign trade correspondence communication, the people having different cultural backgrounds are different in their values and ways of thinking, they will have different understandings on the same information and even get completely different conclusions. The different values formed based on cultural difference cause different management modes and methods while different types of management are easier to cause foreign trade correspondence communication barrier. America is a country featured with high individualism orientation, therefore, the managers in America prefer personal decision-making, advocate competition and award innovation; while China is a country featured with high collectivism orientation, which tends more to collective decision-making and joint responsibility bearing. Under the premise of lacking of foreign trade correspondence communication, Chinese employees tend more accept collective decision-making mode owing to the influence of traditional culture and reject or resist the personal decision-making mode of American managers, which is likely to cause foreign trade correspondence communication barrier thus to cause serious in-coordination in cooperation and even cooperation failure or termination.

\subsection{Difference in Language Communication.}

Language difference is one of remarkable symbols in differentiating foreign trade correspondence communication and one of the largest barriers for foreign trade correspondence communication in enterprise management. Effective communication not only lies in information transmission but also lies in the feeling and understanding of receivers on the information transmission channel smoothness and information meaning. In the foreign trade correspondence communication process, the information sender and receiver as well as the coding and decoding are all influenced and restricted by culture. In the Northern American and Northern European countries including Britain, Germany and Sweden, the people make expressions correctly and basically consider no environmental background; while in Japan, China, France, Spain and Italy as well as the countries in Africa, Asia and the Arab countries in the Middle East, the information transmission not only relies on listened and written things but also relies on the scenario, if one sentence escapes from the specific environmental background, it may have different meanings. Communication and exchange will be difficult to be conducted if the cultural backgrounds and languages of different countries are not understood.

\subsection{Difference in Non-Language Communication.}

The influence of cultural difference on communication process is not only reflected in language communication process but also reflected in non-language communication process. Cultural difference will cause the negotiators of different countries or areas to have large difference in body language and action language applications, and even the same action language transmits completely adverse information. For example, most countries take nodding as agreement. But in India and Nepal, shaking heal represents agreement and affirmation. Moreover, the British people are not willing to speak out their own intentions while Americans like making communication through assembly or slogans with strong visual effect. Furthermore, Japanese generally refuse to envisage the eyes of others and think eye-to-eye conversation is a kind of rude behavior while European and American people think proper eye expression should be retained in conversation, refusing to envisage the eyes of others is the expression of unfriendliness, disdain, guilty, fear, dishonesty, unlikelihood and even quirkiness. Therefore, wrong understanding of the body and action languages of speakers will also cause misunderstanding.

\subsection{Prejudice.}

Prejudice is very common in the foreign trade correspondence communication background. The prejudice hidden in the heart of people will not change easily because of behaviors or personalities of others, therefore, it is difficult to be eliminated, which is the important reason to cause problems in foreign trade correspondence communication and the root of various conflicts and contradictions. Under the cross-cultural background, if you believe in the first impression, you will have an illusion 
of prejudice, which will seriously affect the communication quality and even hinder the communication.

\subsection{Cultural Migration.}

Cultural migration refer to people adopt the national culture criterion and value subconsciously to guide their own actions and thoughts thus to judge the actions and thoughts of others in the foreign trade correspondence communication. In the foreign trade correspondence communication, the people having different cultural backgrounds have difference in attribution pattern, which often becomes the barrier of smooth communication.

\section{Strategy Selection For Enhancing Foreign Trade Correspondence Communication Effectiveness}

\subsection{Deepen the Understanding of Cultural Difference and the Respect to Different Nations, Strive to Realize Cultural Identity.}

Under the underground of globalization management, the cultural diversification and special enlargement have enlarged the complexity, risk and uncertainty of foreign trade correspondence communication. In order to survive, the enterprises should have deep understanding of the local laws, regulations and cultural customs, recognize the cultural difference thus to adjust measures to local conditions, adjust the management thought and communication method in order to enhance the foreign trade correspondence communication effectiveness. Cultural identity refers to realizing the purpose of communicators having sufficient understanding, recognition and respect to other cultures through cross-cultural communication. The effective foreign trade correspondence communication is to realize cultural identity.

\subsection{Largely Advocate and Promote the Internationalized Work Language Application.}

It is needed to largely advocate and promote the internationalized work language application, form the atmosphere of learning and applying multiple languages inside the company. In the cross-cultural communication, effective communication includes three key factors at least: communication subject, receiver and coded information. When the transnational corporations conduct internal communication based on the local language culture and habit of host country by aid of modern communication medium, if the communication content and mode conform to the local habits, and the communicators have no cultural prejudice and rigid relationship, the communication effect will mainly depend on the mastery degree and application ability of host country language culture of transnational corporation managers. If the personnel assigned by the enterprise are skilled in host country language culture, they will perform well in providing customer service, reporting to seniors, communicating with foreign colleagues, communicating and negotiating with competitors and cooperators of various countries.

\subsection{Cultivate the Globalization-Based Managers Consciously.}

Implement the local talent strategy. The currently urgent task of Chinese enterprises is to positively cultivate and reserve a batch of globalization-based managers identifying with the enterprise culture, knowing the strategy development idea and industrial development trend, familiarizing the international conventions and local operation environment, good at communication with personnel from different countries, have full energy and strong entrepreneur spirit, strengthen the cultural sensitivity and cultural adaptation of overseas managers, and assign overseas managers reasonably.

\subsection{Strengthen the Training on Foreign Trade Correspondence Communication and Management, Enhance the Foreign Trade Correspondence Communication Capability.}

Cross-cultural training is one basic means to solve the cultural difference and conduct foreign trade correspondence communication. The managers and employees of Chinese enterprises are strange to the theory, knowledge and method of cross-cultural management, which requires cross-cultural training, including recognition on culture, sensitivity training, language learning, foreign trade correspondence communication and conflict handling as well as regional environment simulation. The training can avoid the overseas personnel to stand on their own cultural position to 
explain and evaluate the actions of others, reduce the possible cultural conflicts, maintain the good and stable interpersonal relationship, maintain the information smoothness and decision-making efficiency inside the enterprise, strengthen the teamwork spirit and enterprise cohesion.

\subsection{Make good for Deficiency and Pay Attention to Enterprise Culture Integration.}

Firstly, face up to the cultural difference thus to differentiate it, find out the commons of different cultures, give full play to the advantages of the two kinds of cultures, find out the combination point, based on the cultural universality recognition, form unified value, common operation value and powerful enterprise culture according to the environment and strategy requirements, which can not only further promote the smooth implementation of foreign trade correspondence communication but also realize the mutual learning and excellence absorbing of different cultures.

\section{Conclusion}

In the language learning process, the learnt native language knowledge of the learners are certain to have positive or negative influence on the learning of target language. This paper conducts analysis based on the current situation of foreign trade English correspondence communication under the cross-cultural underground, combined with the foreign trade characteristic of Guangxi Beibu Gulf Economic Zone, puts forward some effective suggestions on enhancing foreign trade correspondence effectiveness.

\section{Acknowledgements}

This work is supported the following fund:

2017 The student work subject program of Huizhou University:” college students' network addiction of the student work service research" (No, hzxysz201707).

2016 The project of improving the basic ability of young teachers in Colleges and universities in Guangxi:"An empirical study of Guangxi Beibu Gulf Economic Zone Foreign Trade Company foreign trade English correspondence” (No, KY2016YB886).

2016 The higher education research subject project of Hezhou University: "between collaborative innovation researches of entrepreneurial talent cultivation system".

2017 college students' innovative entrepreneurial project: "The agricultural robot autonomous operations research based on machine vision”(No,201711838096) \&\&”Multi-functional autonomous agriculture robot development”(No,201711838121) \&\&”Research and development of navigation system for agricultural robot”(No,201711838008) \&\&”Research and development of data acquisition system and servo control system for mobile platform of agricultural robot" (No,201711838075) \&\&"Research and development of visual navigation system for agricultural robot test platform”(No,201711838076).

2017 Guangxi education science 'ten-three-five' planning project: "Based on set's ICT education platform of fusion, work-integrated learning education training mode research” (No, 2017B107).

\section{References}

[1]. B.Q Li, Y.F Ling, M Tina, and S.Y Zheng: Design and implementation of sugarcane growth monitoring system based on rid and zig bee. International journal of online engineering, 3(14), 96-106, (2018).

[2]. B.Q Li, M Tina, S.Y Zheng, Y.F Ling: design and research of picking manipulator obstacle avoidance system based on iota. International journal of online engineering, 3(14), 96-106, (2018).

[3]. B.Q Li, Y.F Ling, H.Y Zhang, S.Y Zheng: the design and realization of cherry tomato harvesting robot based on iota. International journal of online engineering, 12(12), 23-25, (2016). 
[4]. B.Q Li, W.L Guan, S.Y Zheng, X.G Yue: optimisation design of corn precision Seder based on multi-route and multi-channel control. Journal of the Balkan Tribological Association, 21(4A), 1215, (2015).

[5]. B.Q Li, X.M Yang Guan, S.Y Zheng: Internet of things-based simulation study on Lijiang River water environment monitoring. Journal of coastal research, 79, 1-5, (2017).

[6]. B.Q Li, et al, design of a tea garden ant freezing control system, in: proceedings of the 2016 6th international conference on machinery, materials, environment, biotechnology and computer (mimic), Tianjin, china, 2016, Pp.736-738.

[7]. B.Q Li, Et Al, design of electronic compass, in: proceedings of the 2016 6th international conference on machinery, materials, environment, biotechnology and computer (mimic), Tianjin, china, 2016, pp.1240-1243.

[8]. B.Q Li, et al, research of automatically light-adjusting lamp, in: proceedings of the 2016 international conference on computer engineering, information science \& application technology (icier 2016), Guilin, china, 2016, pp.249-252.

[9]. B.Q Li, et al, the design and realization of fruit harvesting robot based on iota, in: proceedings of the 2016 international conference on computer engineering, information science \& application technology (icier 2016), Guilin, china, 2016, pp.261-264.

[10]. B.Q Li, et al, a new type of automatic opening and closing light-operated curtain, in: proceedings of the 2016 international conference on mechatronics engineering and information technology (iceman), Xian, china, 2016, pp.66-69.

[11]. B.Q Li, et al, design of the intelligent air humidifier, in: proceedings of the 2016 international conference on mechatronics engineering and information technology (iceman), Xian, china, 2016, pp.201-203.

[12]. B.Q Li, et al, the design implementation of the app of experiencing Guangxi folk custom, in: proceedings of the 2016 international conference on economics and management innovations, Wuhan, china, 2016, pp.47-50.

[13]. S.Y Zheng, et al, and digital display design of ethnic clothing of Nanking, in: proceedings of the 4th international conference on mechatronics, materials. Chemistry and computer engineering 2015(icmmcce 2015), Xian, china, 2015, pp.2805-2808.

[14]. S.Y Zheng, et al, design and implementation of supermarket personnel management system based on java, in: proceedings of the 2015 international conference on dedication, management and computing technology(icemct-16), Hangzhou, china, 2016, pp.957-960.

[15]. S.Y Zheng, et al, brief analysis on "heyuantong" campus mobile phone app design, in: proceedings of the 2015 5th international conference on computer sciences and automation engineering, Sonya, china, 2015, pp.151-154.

[16]. S.Y Zheng, et al, social work in teen addiction correction services research under the new situation, in: proceedings of the 2015 4th national conference on electrical, electronics and computer engineering (niece 2015), Xian, china, 2015, pp.252-255.

[17]. B.Q Li, et al, the design of remote temperature monitoring system, in: international conference on green energy and sustainable development, my 27-28, 2017, pp.20-22.

[18]. B.Q Li, et al, design of portable valuables touch alarm circuit, in: international conference on advances in materials, machinery, electronics, 2017, pp.27-32. 
[19]. B.Q Li, et al, design and implementation of a simple acoustic optic dual control circuit, in: 5th international conference on computer-aided design, manufacturing, modelling and simulation, 2017, pp.78-80.

[20]. B.Q Li, et al, design of electronic lock based on single-chip microcomputer, in: 4th international conference on electrical and electronics engineering and computer science, 2017, pp.55-60.

[21]. B.Q Li, et al, the design of chicken house electronic intelligent lighting apparatus, in: international conference on mechanical, electronic, control and automation engineering, 2017, pp.15-20.

[22]. B.Q Li, et al, office automation sub-summary of the work and the project management system, in: international conference on mechanical, electronic, control and automation engineering, 2017, pp.46-48.

[23]. B.Q Li, et al, the design of intelligent heat dissipater control circuit, in: proceedings of the 2017 2nd international conference on materials science, machinery and energy engineering, 2017, pp.22-25.

[24]. B.Q Li, et al, The design of ipv6's transitional scheme in university, in: international conference on materials science, energy technology, power engineering (map), 2017, pp.91-93.

[25]. B.Q li, et al, the personal receiving document management and the realization of email function in oats, in: international conference on materials science, energy technology, power engineering (map), 2017, pp.121-123.

[26]. S.Y Zheng, et al, design and implementation of an audio indicator, in: 5th international conference on computer-aided design, manufacturing, modelling and simulation, 2017, pp.21-23.

[27]. S.Y Zheng, et al, implementation and application of all in campus network, in: international conference on advances in materials, machinery, electronics, 2017, pp.151-153.

[28]. S.Y Zheng, et al, the design of liquid drip speed monitoring device system based on much, in: international conference on green energy and sustainable development, my 27-28, 2017, pp.51-53.

[29]. S.Y Zheng, et al, the design of hearing and hypnosis all-in-one machine, in: international conference on mechanical, electronic, control and automation engineering, 2017, pp.66-68.

[30]. S.Y Zheng, et al, campus network security defines strategy, in: international conference on mechanical, electronic, control and automation engineering, 2017, pp.30-33.

[31]. S.Y Zheng, et al, design and implementation of multifunctional charger, in: international conference on materials science, energy technology, power engineering (map), 2017, pp.71-73.

[32]. B.Q Li, et al, intelligent control management system and its application, in: proceedings of the 2016 international conference on economics and management innovations, Wuhan, china, 2016, pp.68-71.

[33]. B.Q Li, et al, design and implementation of tanks war game based on the android platform, in: proceedings of the 2016 2nd workshop on advanced research and technology in industry applications, Dalian, china, 2016, pp.963-966. 